\title{
IMMUNOMODULATORS ACTING ON COVID-19: ACTUAL KNOWLEDGE AND PERSPECTIVES
}

\author{
Nelson Durán ${ }^{1,2}$ and Wagner J. Fávaro ${ }^{1}$ \\ ${ }^{1}$ Laboratory of Urogenital Carcinogenesis and Immunotherapy, Department of Structural \\ and Functional Biology, University of Campinas, Campinas, SP, Brazil, \\ ${ }^{2}$ Nanomedicine Research Unit (Nanomed), Federal University of ABC (UFABC), Santo \\ André, SP, Brazil.
}

*Correspondence: Prof. Nelson Durán (E-mail: nduran@unicamp.br) and Prof. Wagner José Fávaro (E-mail: favarowj@unicamp.br).

\begin{abstract}
Since the outbreak of SARS CoV-2 infection (Covid-19), healthcare professionals worldwide have been trying to find disease management and control alternatives to encourage immunotherapies. Immunotherapy is an efficient therapeutic option used against comparable viral contaminations such as MERS-CoV and SARS-CoV. The aim of the current study is to assess the existing knowledge associated with SARS-CoV-2 immunotherapy. Information available in published articles and their quality highlights the importance of following strict scientific rules for clinical outcomes. Thus, these studies have shown enough data to confirm that immunomodulation is the main topic investigated in research about Covid-19 therapy. Therefore, it is possible saying that immunotherapy is certainly the appropriate option against this virus.
\end{abstract}

Keywords: COVID-19, Immunotherapy, Immunomodulator, Antibody, Plasma, Immunoglobulins.

\section{Introduction}

Covid-19 appears to be quite different from other SARS-CoV strains. Approximately $85 \%$ of contaminated individuals present mild-to-moderate symptoms, whereas approximately $10 \%$ of them present severe symptoms, approximately $5 \%$ present severe symptoms and half of them end up dying. Interestingly, contamination by Covid19 in children and adolescents is milder than in adult patients; the most significant death rate is associated with elderly and adult individuals with comorbidities such as cardiopathic diseases, diabetes mellitus, among others. If we think about a good explanation for these findings, it is possible hypothesizing that Covid-19 and its interactions with the hosts' immune network can help elucidating the route of Covid-19 infections (Tufani et al., 2020; Saber-Ayad et al., 2020; Remy et al., 2020; Recto et al., 2020; Sanders et al., 2020). Healthy adult individuals present undamaged innate immunity, as well as enhanced humoral and cell-mediated immunity. These conditions 
inhibit infection progression and enable patients to recover within few weeks, since SARS-CoV-2 does not reach their alveoli, differently from critically-ill patients. Elderly patients with, or without, co-morbidities and compromised immune system do not have the same innate and adaptive humoral immune response as healthy patients; thus, SARSCoV-2 often remains mild until it reaches the alveoli, since the blood stream is protected by alveolar lymphocytes and macrophages. The immune system becomes more active in the alveoli because they are the last site for the virus to attack blood circulation. Epithelial cells in airways operate as immune effector molecules and release cytokines, chemokines, among other signaling proteins that play a key role in cell-mediated immunity. Thus, epithelial cells start eradicating infected cells, along with the emergence of systemic cytokines. This process leads to significant damage in lung tissues; therefore, alveoli get full of inflammatory exudates. After some time, patients experience severe hypoxia, as well as lung, liver and kidney damage, because the innate and humoral immunity in their alveoli triggers cell-mediated immunity to set up an extremely dangerous attack at the site. The phenomenon observed in adult and elderly individuals does not explain why children follow a different immunopathogenic path. Abdulamir and Hafidh (2020) have suggested that children's immune system is somehow lesser capable of attacking alveoli and lung tissues.

Assumingly, children's immune system does not have previous memory of coronavirus infection, likely because SARS-CoV-2 shares similar proteins to those found in the common human coronavirus. This is a challenging immunopathogenesis topic that should be thoroughly investigated.

Based on the literature and on data shown in Table 1, almost all immunotherapy assays conducted with $2019-\mathrm{nCoV}$ patients so far incorporate treatments comprising plasma, immunoglobulin, thymosin, tocilizumab, sarilumab, immunoglobulin Fc domain, CR3022, convalescent plasma transfusion, systemic anticoagulation, heparin, statin and interferon. IFN- $\alpha 2 b$, Interferon IFN- $\beta 1 b, B C G$ and OncoTherad have been used to treat SARS-CoV and they can become a promising alternatives against 2019-nCoV. Using immunotherapy against this virus could also be an adequate option (Durán et al., 2019; Fávaro et al., 2019a; AminJafari and Ghasemi, 2020; Delafiori et al., 2020).

It is known that coronavirus infection induces increased levels of T-helper 1 (Th1) cytokine, interferon (IFN)-gamma, inflammatory cytokines such as interleukins IL-1, IL6 and IL-12, and connected cytokines and chemokines such as IL-8, chemokine (C-C motif) ligand 2 (CCL2 protein, also known as monocyte chemoattractant protein-1 or MCP-1) and C-X-C motif chemokine 10 (CXCL10 protein, named as interferon- $\gamma$, induced protein 10 or IP-10) (Mamber et al., 2020; Durán and Fávaro, 2020). The release of these cytokines moderated by these inflammatory and Th1 cytokines activate monocytes/macrophages and neutrophils account for immunopathological outcomes observed for this contamination type.

These hyper-inflammatory immune responses lead to increased Covid-19 severity and, consequently, to high mortality rates. Thus, it is possible saying that hyperinflammatory process inhibition is an unequivocal drug therapy alternative (Mamber et al., 2020; Zhong et al., 2020).

The current review addresses key medications suggested for Covid-19 treatment, based on immunological modulation, which have been reported in the literature, so far. Topics such as immunosuppression and vaccines were not addressed in the current manuscript. 


\section{Antibodies}

Covid-19 antibodies are active subjects; among them one finds tocilizumab and sarilumab, which are the most studied ones; besides, they have recorded the most relevant results. The literature reports several clinical trials on different kinds of immunomodulators (Alijotas-Reig et al., 2020); some of them will be herein addressed. A study conducted with 21 Chinese patients reported that tocilizumab has eliminated lung lesion opacity in $91 \%$ of cases, reduced oxygen intake in $75 \%$ of patients and ventilation was not necessary in approximately $5 \%$ of cases. High C-reactive protein levels significantly decreased in $84 \%$ of patients, whereas lymphocytes got back to normal levels in $53 \%$ of cases (Xu et al., 2020). Another trial conducted with tocilizumab in China was lately approved by the National Health Commission of the People's Republic of China to be used in patients suffering with acute SARS-CoV-2 pulmonary implications (CCTR, 2000). Accordingly, sarilumab - which is an anti-human IL-6 receptor monoclonal antibody presenting activity similar to that of tocilizumab - started being used to treat rheumatoid arthritis. Sarilumab is capable of blocking IL-6, just like tocilizumab does; thus, it may have positive effects on Covid-19 patients presenting acute expressions of the infection and high IL6 levels. A phase II-III clinical trial was recently implemented in USA and in five European Countries (Eur. Pharm. Reviev. Report, 2020).

Although anakinra is an immunosuppressor used against IL-1 (anti-IL-1), it is another medicinal alternative to treat patients with acute Covid-19. It is a recombinant and superficially transformed type of human interleukin 1 receptor antagonist protein (IL$1 \mathrm{Ra}$ ). This protein is naturally liberated by monocytes and tissue macrophages that bind to IL-R and regulate its action. IL-1 blockade leads to inflammatory response suppression (Calabrese, 2003). Based on a phase-III randomized controlled trial, anakinra was capable of increasing the survival rate of patients with sepsis without increased adverse effects (Shakoory et al., 2016).

Ten clinical trials focused on investigating the effects of anakinra application in Covid-19 patients have started in May 2020 and remain in progress (Alijotas-Reig et al., 2020). As previously mentioned, anakinra is capable of inhibiting pro-inflammatory cytokines such as interleukin (IL)-1 $\alpha /$ IL- $1 \beta$; data have shown its effectiveness in treating macrophage activation syndrome generated by several inflammatory circumstances, as well as in small assays conducted with Covid-19 patients (Aouba et al., 2020; Cavalli et al., 2020).

\section{Immunoglobulins/Heparin}

Preliminary studies have shown the effectiveness of intravenous immunoglobulin (IVIg) applications in the therapy of patients with acute inflammatory discomfort associated with influenza and SARS-CoV infections. A study reported the effectiveness of high IVIg immunoglobulin doses in 3 Covid-19 patients (Cao et al., 2020). However, it is necessary conducting further studies with a larger number of Covid-19 patients in order to validate this clinical outcome. Thus, a randomized controlled clinical trial based on IVIg immunoglobulin application in patients with acute SARS-CoV-2 infection was implemented (Clinical Trial.gov: NCT 04261426) (Alijotas-Reig et al., 2020).

Alijotas-Reig et al. (2020) have pointed out two potentially unfavorable effects of acute IVIg use that may have harmful survival effect on patients with acute Covid-19, namely: 1) Adverse effect presenting high death rate, called TRALI (transfusion (immunoglobulin)-related severe lung injury), which comprises severe respiratory distress syndrome within few perfusion hours (Li et al., 2020); 2) and thrombotic events associated with IVIg therapy, whose estimated incidence reaches up to $17 \%$ ( $\mathrm{Li}$ et al., 2020). The aforementioned authors suggested that, due to the dubious effectiveness of 
IVIg therapy in patients with SARS-CoV and to their likely risk of developing acute lung injury and thrombosis, IVIg should be carefully applied to Covid-19 patients as alternative therapy. Besides, according to comments by Alijotas-Reig et al. (2020) about preliminary reports on convalescent plasma/hyperimmune immunoglobulin therapy, this treatment was capable of decreasing patient mortality rates, mainly when it was applied at early stages of the disease, right after symptoms onset. However, the true effectiveness of this therapy remains controversial; thus, the aforementioned authors have suggested that this treatment should be assessed through well-designed clinical trials (Shen et al., 2020).

Similarly to SARS-CoV patients, Covid-19 patients in acute conditions can develop disseminated intravascular coagulation, arterial thrombosis and pulmonary thromboembolism (PTE), which is one of the reasons why different diagnostic alternatives were suggested for Covid-19 patients with clinical suspicion of PTE (Zuckier et al., 2020). Besides, 50 Covid-19 patients subjected to autopsy presented microthrombosis and, in some cases, thrombus involving wide pulmonary artery regions. Histological analyses have shown that alveolar and interstitial inflammation spread towards juxtaposed pulmonary vasculature, as well as the normal circulatory fibrinogen amounts and local fibrinolysis with high D-dimer (fibrin degradation product (FDP) formation, small protein fragment in the blood) at the initial stage of Covid-19 pneumonia, were not associated with severe onset of macrophage activation syndrome/hemophagocytic syndrome (McGonagle et al., 2020). This hyperinflammatory intra-pulmonary infection may influence patients' trend to develop acute regional vascular dysfunction, together with microthrombosis and hemorrhage. This process leads to lung centric pulmonary intravascular coagulopathy that resembles disseminated intravascular coagulation (Shoenfeld, 2020).

Some patients presented significantly abnormal coagulation function, which suggests that the initial intravenous immunoglobulin application and the low molecular weight heparin anticoagulation treatment were very relevant. This treatment is recommended for Covid-19 patients who present elevated D-Dimer levels (Li et al., 2020). Tang et al. (2020) found the progress of clot activation markers that have reduced the rate of death by Covid-19 when heparin was administered. Besides, heparin has pharmacological effects other than the antithrombotic ones. It also has anti-inflammatory and immune-modulating properties. Low-molecular weight heparin (LMWH) enables the survival of human endothelial cells undergoing apoptosis in response to TNF- $\alpha$ (tumor necrosis factor-alpha) binds to antiphospholipid antibodies and stops complement pathway activation (Lim, 2011; Carr and Cho, 2007). Interestingly, fondaparinux (saccharide with antithrombotic activity) is often used in heparin-allergy cases and presents excellent results. All these outcomes are associated with viral infections (e.g., SARS-CoV, SARS-CoV-2) and end up presenting antiphospholipid antibodies with potential pathogenic effects (Zhang et al., 2020). It is possible saying that the heparinbased anticoagulant therapy helps avoiding thrombosis and simultaneously downregulates pro-inflammatory pathways (Alijotas-Reig et al., 2020).

A clinical trial comprising 2,075 Covid-19 patients subjected to heparin therapy, as well as to others drugs, was conducted in 17 hospitals in Spain; results have shown that 301 patients died, 1,447 were discharged from hospital, 201 remained hospitalized and 126 were transferred to other hospitals (these patients were excluded from the study) heparin was used in 1,734 patients after this study. Finally, heparin was associated with reduced mortality rates when the model was adjusted based on patients' age and sex (Ayerbe et al., 2020). 
A clinical trial was conducted with 99 Covid-19 patients treated with heparin (mainly with low molecular-weight heparin) for a week or longer. There was no difference in 28-day mortality between heparin users and non-users. However, the 28-day mortality of heparin in patients with SIC (sepsis-induced coagulopathy) was lower than that of non-users; score $\geq 4$ or D-dimer $>6$-fold the upper normal limit. Then, anticoagulant therapies, mostly the ones based on low molecular-weight heparin, are associated with better prognosis in acute Covid-19 patients who meet SIC criteria or present significantly high D-dimer levels (Tang et al., 2020).

Another clinical trial run in a hospital reported low mortality rate among 786 Covid-19 patients treated with anticoagulation drugs (no anticoagulant name was mentioned) (Paranjpe et al., 2020)

Actually, several clinical trials are currently recruiting patients for heparin therapy (NCT04401293-USA; NCT04345848-Switzerland; NCT04367831-USA; NCT 04373 707-France; NCT04366960-Italy; NCT04362085-Canada; NCT04359277-USA).

\section{Statins}

Statins trigger strong inhibition - via protein geranyl-geranylation - of proinflammatory cytokine production (IL-6, $-8,-10$. and TNF- $\alpha$ ) in synovial and endothelial mononuclear cells. Besides, they act as T-cell inhibitors (e.g., activation and/or proliferation) and trigger immunomodulatory activity.

Statins also preserve the gene expression of myeloid differentiation primary response 88 (MyD88) at normal levels during hypoxia and mitigate the activation of factor nuclear kappa $\mathrm{B}(\mathrm{NF}-\kappa \mathrm{B})$. These features explain the trend to use statins to treat Covid-19 infection (Fedson et al., 2020). Accordingly, in a murine model a high pathogenic infection, abnormal signaling coming from a lack of toll-like receptors (TLRs) adaptor TRIF or MyD88 causes severe respiratory distress syndrome (ARDS) as principal reason of mortality in SARS-CoV disease (Totura and Baric, 2015). MyD88 operates downstream TLRs and results from SARS-CoV contamination. In addition, either the under-expression or over-expression of the MyD88 gene is associated with increased mortality rates after MERS-CoV infection. Thus, an NF- $\kappa \mathrm{B}$ downstream TLRs-MyD88 pathway is triggered by coronavirus infections. This is an interesting finding, since NF$\kappa \mathrm{B}$ inhibition has improved lung infection and survival rates in murine models subjected to SARS-CoV infection. It may have happened due to counterbalancing activation of other innate immune factors. Although many US hospitals have incorporated statin to Covid-19 therapies applied to patients, some concerns about its use remain and caution must be taken at the time to adopt such an alternative (Dashti-Khavidaki and Khalili, 2020).

Despite all these comments about statin use in Covid-19 patients, a clinical trial was conducted with 154 Covid-19 positive patients, who were treated with a combination of angiotensin-converting enzyme inhibitors (ACEi)(e.g., captopril)/angiotensin II receptor blockers (ARB) (e.g., losartan) and/or statin (e.g., simvastatin). Results have shown statistically significant association between statin intake and lack of symptoms in Covid-19 infection cases. This association remained statistically significant when patients were assessed based on age, sex, diabetes mellitus, hypertension and functional status. There was not statistically significant association between ACEi/ARB and asymptomatic status or severe clinical outcome. Based on these data, statin intake by elderly, fragile individuals can be associated with substantial beneficial effect on Covid-19-associated clinical symptoms (De Spiegeleer et al., 2020).

\section{Interferon}


Data showing that interferon reacts to coronaviruses in a way different from that to other respiratory viruses is an important finding (Blanco-Melo, et al., 2020). Trials assaying the application of type I or type III interferons are already in course. Type I interferon (IFN $\alpha \beta$ ) receptors are ubiquitously expressed, whereas type I interferons can lead to antiviral effects; however, they can also induce immune cell activation and increase tissue pathologies (Broggi et al., 2020; Merad and Martin, 2020). Moreover, SARS-CoV-2 did not efficiently induce types I, II, or III interferons in human lung tissues infected ex-vivo as it happened with 2003 SARS-CoV (Chu et al., 2020). Thus, interferon therapy application to jump-start or enhance patients' antiviral response would be an obvious approach (Hung et al., 2020).

Interferon (IFN)- $\alpha 2 \mathrm{~b}$ application was investigated in a cohort of Covid-19 positive cases in China; 77 adult individuals infected with Covid-19 were treated with either nebulized IFN- $\alpha 2 b$ or arbidol (Umifenovir), or with the combination of both. All serial SARS-CoV-2 tests were conducted; IFN- $\alpha 2 b$ application in separate, or in association with arbidol, has effectively shorten the time the virus remained detectable in patients' upper respiratory tract and simultaneously diminished the length of high blood levels recorded for inflammatory markers such as IL-6 and C-reactive protein. Although it was a non-controlled exploratory study, results have suggested that IFN- $\alpha 2 b$ should be further investigated as therapy for Covid-19 patients (Zhou et al., 2020).

A clinical trial was conducted with 127 patients treated with triple antiviral therapy based on interferon beta- $1 \mathrm{~b}$ (IFN- $\beta 1 \mathrm{~b}$ ), lopinavir/ritonavir and ribavirin (Clinical trial gov-NCT04276688). The triple antiviral therapy was safe and better than the use of lopinavir/ritonavir alone, since it mitigated virus dissemination, relieved patients' symptoms and enabled individuals with mild-to-moderate Covid-19 to be discharged from hospital. The interferon/lopinavir/ritonavir/ribavirin association has also diminished IL-6 levels. The clinical and antiviral efficiency of this association enabled shorter hospital stays and better infection control (Hung et al., 2020). Other clinical trials associated with antiviral drugs are currently in progress (IFN- $\beta 1 b$ : NCT04350684-Iran; NCT04350671-Iran; IFN- $\lambda$ : NCT04343976-USA) (Saber-Ayad et al., 2020).

\section{Immunotherapies: BCG (Bacillus Calmette-Guérin) and OncoTherad}

The recent Covid-19 outbreak has made the association between BCG vaccination and Covid-19 morbidity and mortality rates reemerge in several countries (Miller et al., 2020; Hegarty et al., 2020; Salas and Miyakawa, 2020; Shet et al., 2020; Goswami et al., 2020; Hensel et al., 2020; Berg et al., 2020; Kirov, 2020; Dayal and Gupta, 2020; Szigeti et al., 2020). Some studies have shown significant association between BCG vaccination and Covid-19 incidence, and likely mortality, in countries counting on BCG vaccination policies (WHO, 2020; Soliman et al., 2020).

According to Soliman et al (2020), there is robust evidence about the association between BCG vaccination and prevention of severe respiratory infections. This statement meets information from data available in some systematic reviews; one of them incorporated a meta-analysis and a randomized controlled trial (RCTs), which evidenced a high confirmation level for prevention studies (CEBM 2019; Soliman et al., 2020).

Clinical trials are currently in progress and recruiting participants to determine whether BCG vaccination helps protecting healthcare workers working in the front lines of the Covid-19 pandemic and in other pandemic situations in different countries (Clinical trial gov.: NCT04327206-Australia; NCT04328441-Netherlands; NCT04379336-South Africa; NCT04347876-Egytp; NCT 04414267-Greece; NCT04373291-Denmark; NCT04348370-USA). 
As previously mentioned, patients' immune response to SARS-CoV-2 pulmonary infection involves a series of cytokines (IL-1B, IFN- $\gamma$, IP10, MCP1 and TNF- $\alpha$ ) identified at higher concentrations in the plasma of infected individuals (Huang et al., 2020). Robust adaptive immune response to viral clearance through IFN- $\gamma$ requires early type-1 IFN response. However, previous knowledge has shown that cytokine dysregulation is the main feature of early SARS-CoV infection; CoV-cell recognition and type-1 IFN response dynamics may determine patients' pro- or anti-inflammatory immune response and injury severity (Sarzi-Puttini et al., 2020; Dandekar and Perlman, 2005). Therefore, immunomodulators capable of controlling early cytokine response, such as the recruitment of effector cells and viral clearance, may be a good strategy to be used against SARS-CoV-2.

Several studies have successfully defeated CoVs based on direct IFN administration to patients. The combination of type-I IFN and IFN- $\gamma$ was capable of synergistically inhibiting virus replication in vitro (Yoshikawa et al., 2010). Larkin et al. (2003) have indicated that the combination of IFN- $\alpha$ and IFN- $\gamma$ in vitro enabled strong synergistic antiviral activity at much lower IFN doses than often necessary. Reducing the IFN dose in combination therapies has the advantage of reducing unwanted adverse reactions in patients. Nagata et al. (2008) described the destructive effect of cytokine storm in adult mice after SARS-CoV infection. Although intravenous TNF- $\alpha$ injection did not show beneficial effects, intraperitoneal IFN- $\gamma$ injection has protective effect on SARS-CoV infection. Scagnolari et al. (2004) also reported the synergistic effects of IFN$\gamma$ and IFN- $\beta$ on SARS-CoV-infected Vero cells. Thus, IFN induction can play a fundamental role in protecting the human body from $\mathrm{CoV}$ infections.

Accordingly, immunotherapy with OncoTherad stands out as a potential treatment for Covid-19. The research team of the Urogenital Carcinogenesis and Immunotherapy Laboratory (UNICAMP), produced an immunomodulator and registered as OncoTherad. OncoTherad works as Biological Response Modifier and contributes to local immune system activation in tumor microenvironments. Pre-clinical, clinical-veterinary and Phase I/II clinical studies conducted with humans have shown that immunotherapy with OncoTherad has activated patients' innate immune system mediated by Toll-like receptors (TLRs) 2 and 4; this process resulted in increased interferon signaling pathway (TLR4, TRIF, IRF3, INF- $\gamma$ ), which is associated with the greater effectiveness of this nano-immunotherapy to treat non-muscle invasive bladder cancer (NMIBC) in comparison to standard treatments with BCG (Bacillus Calmette-Guérin). OncoTherad was capable of decreasing RANK/RANK-L system expression in animal models and, consequently, of preventing metastases formation and/or progression (Fávaro and Durán, 2017; Böckelmann et al., 2019; Durán et al., 2019; Fávaro et al., 2019ab; Fávaro and Durán, 2020).

A prospective, monocentric clinical study (Hospital Municipal de Paulínia, São Paulo, Brazil), based on phase I/II single-arm immunotherapy with OncoTherad, was conducted with patients refractory to BCG treatment. Results have shown that this treatment promoted recurrence-free survival rate (complete response) of approximately $80 \%$ in the 24-month follow-up; this outcome shows that this immunotherapy was better than the standard treatment with BCG and/or intravesical chemotherapy, a fact that makes OncoTherad a beneficial therapeutic option to treat NMIBC. This assay has also shown significantly increased immunoreactivity to TLR4, TRIF, IRF-3, INF- $\gamma$ and iNOS in primary lymphoid follicle regions in the bladder, as well as significantly low adverse effects (Fávaro et al., 2019b; Alonso et al., 2020)

Based on the action mechanism of the OncoTherad-based immunotherapy and on the role played by the interferon signaling pathway in controlling Covid-19 infection, it 
was possible identifying the potential action of this immunotherapy to control SARSCoV-2 infection in 5 NMIBC patients (CAAE: 93619718.7.0000.5404; Brazilian Clinical Trial RBR-6swqd2). who tested positive for Covid-19.

The most emblematic case among the herein evaluated ones was the case report about a 78-year-old Brazilian male patient with history of systemic arterial hypertension, anterior myocardium revascularization and former smoker, who was recruited for the OncoTherad clinical trial to attend BCG-refractory or relapsed high grade-NMIBC. After interrupting the treatment for a certain period-of-time due to an international trip, he arrived at the Hospital with Covid-19 symptoms. All analyses have shown advanced Covid-19 stage; the patient was treated with OncoTherad, in association with chemotherapy support and ventilation; he was discharged at the 10th hospitalization day (Delafiori et al., 2020). Besides all these data, patient's clinical improvement was featured by high free fatty acid, acylcarnitine and phosphatidylglycerol (PG) levels (based on deep leaning technique carried out through mass spectrometry), which reinforced previous findings about serum metabolome (Wu et al., 2017) in recovered SARSCoV patients.

The other 4 patients subjected to the clinical protocol based on OncoTherad application to NMIBC cases who tested positive for Covid-19 have shown similar behavior to that of the patient described in the aforementioned case report. The evolution and recovery of patients who received OncoTherad immunotherapy took shorter time (10 days) than that observed for patients subjected to the standard treatment. Thus, if one takes into consideration patients' age and comorbidities, it is possible assuming that the immunotherapy with OncoTherad has played a protective role in stopping the evolution of Covid-19 infection to the most severe stages of it and in promoting patients' fast recovery without the need of hospitalization in Intensive Care Units (Delafiori et al., 2020). Actually, patients presenting these conditions have been recruited to receive OncoTherad therapy in a Clinical trial in progress at Hospital Municipal de Paulinia in São Paulo, Brazil (MS-Brazil, 2020).

\section{Final remarks}

Since the outbreak of Covid-19 in December 2019, different new and old pharmaceutical materials have been tested in a large number of clinical trials focused on assessing their effectiveness against SARS CoV-2 infection. The first strategy lied on using anti-rheumatic drugs, likely due to their immunomodulating or immunosuppressing properties; however, many aspects related to their applications should be taken into consideration. Zhong et al. (2020) have pointed out aspects such as hyper-inflammation and viral replication (hyper-activation of immune response leads to tissue damage and organ failure), immunomodulation treatment timing (important and direct evidences deriving from randomized controlled trial are required to determine the appropriate treatment timing for patients with Covid-19) and pharmacokinetics of oral medications (administration route is an important factor).

Immunotherapy is an effective alternative treatment against Covid-19; the main methods mentioned in the current study were capable of enhancing clinical outcomes in Covid-19 infected patients. Several trials yet in progress will certainly help better understanding the potential action of immunomodulation treatments on Covid-19 infection associated with hyper-inflammation processes.

\section{Acknowledgments}


The authors would like to thank the São Paulo Research Council (FAPESP grant 2014/11154-1; 2018/10052-1), and the Brazilian National Council for Scientific and Technological Development (CNPq grant 552120/2011-1) Brazil.

\section{REFERENCES}

Abdulamir AS, Hafidh RR. The possible immunological pathways for the variable immunopathogenesis of COVID-19 Infections among healthy adults, elderly and children. Electron J Gen Med. 2020; 17:em202.

Alijotas-Reig J, Esteve-Valverde E, Belizna C, et al. Immunomodulatory therapy for the management of severe COVID-19. Beyond the anti-viral therapy: A comprehensive review. Autoimmun Rev. 2020; 19: 102569 (and references therein).

Alonso JCC, Reis IB, Gonçalves JM, et al. Oncotherad immunotherapy elicits promising responses in Bacillus Calmette-Guérin-unresponsive non-muscle invasive bladder cancer: Results from phase I/II study. J Clin Oncol. 2020; 38: e17048. Doi:10.1200/JCO.2020.38.15_suppl.e17048.

AminJafari A, Ghasemi S. The possible of immunotherapy for COVID-19: A systematic review. Inter Immunopharmacol. 2020; 83:106455

Aouba A, Baldolli A, Geffray L, et al. Targeting the inflammatory cascade with anakinra in moderate to severe COVID-19 pneumonia: case series. Ann Rheum Dis. 2020; published online May 6. DOI:10·1136/ annrheumdis-2020-217706.

Ayerbe L, Risco C, Ayis S. The association between treatment with heparin and survival in patients with Covid-19. J Thromb Thrombol. 2020; https://doi.org/ $10.1007 / \mathrm{s} 11239-020-02162-\mathrm{Z}$

Berg M, Yu Q, Salvador C, et al. Mandated Bacillus Calmette-Guérin (BCG) vaccination predicts flattened curves for the spread of COVID-19. medRxiv. 2020; https://doi.org/10.1101/2020.04.05.20054163.

Blanco-Melo, D. Nilsson-Payant BE, Liu W-C, et al. Imbalanced host response to SARSCoV-2 drives development of COVID-19. Cell. 2020; 181, 1036-1045.

Böckelmann PK, Tizziani SHS, Durán N, et al. New Therapeutic Perspective for Bladder Cancer in Dogs: Toxicological and clinical evaluation of bladder cancer in dogs by a nanostructured pharmaceutics (OncoTherad). J. Phys. Conf. Ser. 2019; 1323: 012022.

Broggi A, Granucci F, Zanoni I. Type III interferons: balancing tissue tolerance and resistance to pathogen invasion. J. Exp. Med. 2020; 217: e20190295.

Calabrese LH. Molecular differences in anticytokine therapies. Clin Exp Rheumatol. 2003;21:241-248.

Cao W, Liu X, Bai T, et al. High-dose intravenous immunoglobulin as a therapeutic option for deteriorating patients with coronavirus disease 2019. Open Forum Infect Dis. 2020; 7: ofaa102.

Carr JA, Cho JS. Low molecular weight heparin suppresses tumour necrosis factor expression from deep vein thrombosis. Ann Vasc Surg. 2007; 21:50-55.

Cavalli G, De Luca G, Campochiaro C, et al. Interleukin-1 blockade with high-dose anakinra in patients with COVID-19, acute respiratory distress syndrome, and hyperinflammation: a retrospective cohort study. Lancet Rheumatol. 2020; https:// doi.org/10.1016/S2665-9913(20)30127-2.

CEBM 2009. March Levels of Evidence 2009. 2009; at: https://www.cebm.net/ 2009/06/oxford-centre-evidence-based-medicine-levels-evidence-march-2009/

CCTR-2020. Chinese Clinical Trial Registry. A multicenter, randomized controlled trial for the efficacy and safety of tocilizumab in the treatment of new coronavirus 
pneumonia [COVID-19]. 2020; Register number: ChiCTR2000029765; http://www.chictr.org.cn/ showprojen.aspx?proj=49409

Chu H, Chan JF-W, Wang Y, et al. Comparative replication and immune activation profiles of SARS-CoV-2 and SARS-CoV in human lungs: an ex vivo study with implications for the pathogenesis of COVID-19. Clin Infect Dis. 2010; ciaa410, https://doi.org/10.1093/cid/ciaa410

Dayal D, Gupta S. Connecting BCG Vaccination and COVID-19: Additional data. medRxiv. 2020; https://doi.org/10.1101/2020.04.07.20053272.

Dandekar AA, Perlman S. Immunopathogenesis of coronavirus infections: implications for SARS. Nat Rev Immunol. 2005; 5: 917-927.

Dashti-Khavidaki S, Khalili H. Considerations for statin therapy in patients with COVID19. Pharmacotherapy. 2020; 40: 484-486 (and references therein).

De Spiegeleer A, Bronselaer A, Teo JT, et al. The effects of ARBs, ACEIs and statins on clinical outcomes of 2 COVID-19 infection among nursing home residentes. medRxiv. 2020; Doi: https://doi.org/10.1101/2020.05.11.2009634.

Delafiori J, Alonso JCC, dos Santos LA, et al. 78-Year old urothelial cancer patient with faster recovery from COVID-19: potential benefit from adjuvant active immunotherapy. SSRN. 2020; http://dx.doi.org/10.2139/ssrn.3609259.

Durán N, Fávaro WJ. Pyroptosis: Physiological roles in viral infection. ArXiv. 2020; Submitted .

Durán N, Dias QC, Fávaro WJ. OncoTherad: A New Nanobiological Response Modifier, its Toxicological and Anticancer Activities. J Phys Conf Ser. 2019; 1323: 012018.

European Pharmaceutical Review Report. Global trial to evaluate Kevzara ${ }^{\circledR}$ [sarilumab] as COVID-19 therapy initiated. Available at: https://www. European pharmaceuticalreview.com/news/116003/global-trial-toevaluatekevzarasarilumab-as-covid-19-therapy-initiated/; 2020 [accessed on April, 4, 2020].

Fávaro WJ, Durán N. Process of obtaining a nanostructured complex (CFI-1), associated to nanostructured CFI-1 with a protein (MRB-CFI-1) and its use. Brazilian Patent PIBR. 10.2017.012768.0. 2017.

Fávaro WJ, Durán N. A method for producing a nanostructured complex (cfi-1), a protein-associated nanostructured complex (mrb-cfi-1) and use. US Patent. US20200156951A1.

Fávaro WJ, Lantas SR, Gonçalves JM, et al. Role of OncoTherad immunotherapy in the regulation of toll-like receptors-mediated immune system and RANK/RANKL signaling: New therapeutic perspective for non-muscle invasive bladder cancer. $J$ Clin Oncol. 2019a; 37: e16004.

Fávaro WJ, Lantas SR, Gonçalves JM, et al. Single-arm phase I/II study of the safety and efficacy of OncoTherad immunomodulator in patients BCG-refractory or relapsed non-muscle invasive bladder cancer. J Clin Oncol. 2019b; 37: e16000.

Fedson DS, Opal SM, Rordamc OM. Hiding in plain sight: An approach to treating patients with severe COVID-19 infection. mBio. 2020;11: e00398-20.

Goswami R, Mittal D, and Goswami R. Interaction between malaria transmission and BCG vaccination with COVID-19 incidence in the world map: A cross-sectional study. medRxiv. 2020; https://doi.org/10.1101/2020.04.03.20052563.

Hegarty P, Kamat A, Zafirakis H, and DiNardo A. BCG vaccination may be protective against Covid-19. Preprint. ResearchGate. 2020; DOI: 10.13140/RG.2.2. 35948.10880.

Hensel J, McGrail D, and McAndrews K, et al. Exercising caution in correlating COVID19 incidence and mortality rates with $\mathrm{BCG}$ vaccination policies due to variable rates 
of SARS CoV-2 testing. medRxiv. 2020; https://doi.org/10.1101/ 2020. 04.08.20056051.

Huang C, Wang Y, Li X, et al. Clinical features of patients infected with 2019 novel coronavirus in Wuhan, China. Lancet. 2020; 395: 497-506.

Hung IF-N, Lung K-C, Tso EY-K, et al. Triple combination of interferon beta-1b, lopinavir-ritonavir, and ribavirin in the treatment of patients admitted to hospital with COVID-19: an open-label, randomized, phase 2 trial. Lancet 2020; 395: 16951704.

Kirov S. Association between BCG policies is significantly confounded by age and is unlikely to alter infection or mortality rates. medRxiv. 2020; https:// doi.org/10.1101/2020.04.06.20055616.

Kruse RL. Therapeutic strategies in an outbreak scenario to treat the novel coronavirus originating in Wuhan, China. F1000Res 2020; 9: 72.

Larkin J, Jin L, Farmen M, et al. Synergistic antiviral activity of human interferon combinations in the hepatitis $\mathrm{C}$ virus replicon system. J Interferon Cytokine Res. $2003 ; 23: 247-257$.

Li T, Lu H, Zhang W. Clinical observation and management of COVID-19 patients. Emerg Microbes Infect. 2020; 9:687-690.

Lim W. Complement and the antiphospholipid syndrome. Curr Opin Hematol. 2011; 18:361-365.

Mamber SW, Krakowka S, Osborn J, et al. Could Unconventional Immunomodulatory Agents Help Alleviate COVID-19 Symptoms and Severity? Preprints (www.preprints.org). 2020; Doi:10.20944/preprints202004.0014.v1.

Merad M, Martin JC. Pathological inflammation in patients with COVID-19: a key role for monocytes and macrophages. Nat Rev Immunol. 2020; 20: 355-362,

McGonagle D, Sharif K, O'Regan A, et al. The role of cytokines including interleukin-6 in COVID-19 induced pneumonia and macrophage activation syndrome-like disease. Autoimmun . 2020, 19: 102537.

Miller A, Reandelar M, Fasciglione K, et al. Correlation between universal BCG vaccination policy and reduced morbidity and mortality for COVID-19: an epidemiological study. medRxiv. 2020. Doi: https://doi.org/10.1101/2020.03. 24.20042937.

MS-2020-Brazil. Bulletin Brazilian Health Ministry. Daily Report of Evidences-COVID19 No51. https://portalarquivos.saude.gov.br/images/pdf/2020/June/16/ N51Informe Diario-referente-16-06.pdf.

Nagata N, Iwata N, Hasegawa $\mathrm{H}$, et al. Mouse-passaged severe acute respiratory syndrome-associated coronavirus leads to lethal pulmonary edema and diffuse alveolar damage in adult but not young mice. Am J Pathol. 2008; 172:1625-1637.

Paranjpe I, Fuster V, Lala A, et al. Association of treatment dose anticoagulation with inhospital survival among hospitalized patients with COVID-19. J Am Coll Cardiol. 2020; https://doi.org/10.1016/j.jacc.2020.05.001

Recto MST, Tan FM, Cuajunco EA, et al. (Eds). A review of immunomodulators as therapeutic interventions for moderate to severe COVID-19 infections. Philippine Soc Allerg Asth Immunol Inc. 2020; 2020: 1-97. https://pps.org.ph/wpcontent/uploads/2020/04/LOGO-PSAAI-COVID-19-Immunomodulator-Review4-22-2020-DBA1.pdf.

Remy KE, Brakenridge SC, Francois B, et al. Immunotherapies for COVID-19: lessons learned from sepsis. Lancet Respir Med. 2020; https://doi.org/10.1016/S22132600(20)30217-4. 
Saber-Ayad M, Saleh MA, Abu-Gharbieh E. The rationale for potential pharmacotherapy of COVID-19. Pharmaceuticals. 2020; 13: 96.

Sala G and Miyakawa T. Association of BCG vaccination policy with prevalence and mortality of COVID-19. medRxiv. 2020; https://doi.org/10.1101/ 2020. 03.30. 20048165

Sanders JM, Monogue ML, Jodlowski TZ, et al. Pharmacologic treatments for coronavirus disease 2019 (COVID-19). A review. JAMA. 2020; 323:1824-1836.

Sarzi-Puttini P, Giorgi V, Sirotti S, et al. COVID-19, cytokines and immunosuppression: what can we learn from severe acute respiratory syndrome? Clin Exper Rheumatol. 2020; 38: 337-342.

Scagnolari C, Vicenzi E, Bellomi F, et al. Increased sensitivity of SARS-coronavirus to a combination of human type I and type II interferons. Antivir Ther. 2004; 9:10031011.

Shakoory B, Carcillo JA, Chatham WW, et al. Interleukin-1 receptor blockade is associated with reduced mortality in sepsis patients with features of macrophage activation syndrome: reanalysis of a prior phase III trial. Crit Care Med. 2016; 44: 275-281.

Shen C, Wang Z, Zhao F, et al. Treatment of 5 critically ill patients with COVID-19 with convalescent plasma. JAMA. 2020; 323:1582-1589.

Shet A, Ray D, Malavige N, Santosham M, Bar-Zeev N. Differential COVID-19attributable mortality and BCG vaccine use in countries. medRxiv. 2020; https:// doi.org/10.1101/2020.04.01.2004947804.01.20049478.

Shoenfeld Y. Corona (COVID-19) time musings: our involvement in COVID-19 pathogenesis, diagnosis, treatment and vaccine planning. Autoimmun Rev. 2020; 19: 102538 .

Soliman R, Brassey J, Plüddemann A, et al. Does BCG vaccination protect against acute respiratory infections and COVID-19? A rapid review of current evidence. CEBMOxford. 2020; https://www.cebm.net/covid-19/does-bcg-vaccination-protectagainst-acute-respiratory-infections-and-covid-19-a-rapid-review-of-currentevidence/

Szigeti R, Kellermayer D, Kellermayer R. BCG protects against COVID-19? A word of caution. medRxiv. 2020; https://doi.org/10.1101/2020.04.09.20056903.

Tang N, Bai H, Chen X, et al. Anticoagulant treatment is associated with decreased mortality in severe coronavirus disease 2019 patients with coagulopathy. J Thromb Haemost. 2020; 18:1094-1099.

Tang N, Bai H, Chen X, et al. Anticoagulant treatment is associated with decreased mortality in severe coronavirus disease 2019 patients with coagulopathy. J Thromb Haemost. 2020; 18: 1094-1099.

Tian X, Li C, Huang A, et al., Potent binding of 2019 novel coronavirus spike protein by a SARS coronavirus-specific human monoclonal antibody. Emerg Microbes Infect. 2020; 9: 382-385.

Totura AL, Baric RS. 2015. Reply to Statins may decrease the fatality rate of MERS infection. mBio 2015; 6: e01303-15.

Tufani A, Güler AA, Matucci-Cerinic M. COVID-19, immune system response, hyperinflammation and repurposing antirheumatic drugs. Turk J Med Sci. 2020; 50: 620-632.

WHO. 2020. Bacille Calmette-Guérin (BCG) vaccination and COVID-19. Scientific brief. 2020. https://www.who.int/news-room/commentaries/detail/bacillecalmette-gu\%C3\%A9rin-(bcg)-vaccination-and-covid-19 
Wu Q, Zhou L, Sun X, et al. Altered lipid metabolism in recovered SARS patients twelve years after infection. Sci Rep. 2017; 7: 9110.

Xu X, Han M, Li T, et al. Effective treatment of severe COVID-19 patients with tocilizumab. Proc Natl Acad Sci USA. 2020; 117: 10970-10975.

Yoshikawa T, Hill TE, Yoshikawa N, et al. Dynamic innate immune responses of human bronchial epithelial cells to severe acute respiratory syndrome-associated coronavirus infection. PLoS One. 2010; 5: e8729.

Zhang Q, Wang Y, Qi C, et al. Clinical trial analysis of 2019-nCoV therapy registered in China. J Med Virol. 2020; 92: 540-545.

Zhang Y, Xiao M, Zhang S, et al. Coagulopathy and antiphospholipid antibodies in patients with Covid-19. N Engl J Med. 2020; 382: e38.

Zhong J, Tang J, Ye C, et al. The immunology of COVID-19: is immune modulation an option for treatment? Lancet Rheumatol. 2020; https://doi.org/10.1016/S2665-9913 (20)30120-X

Zhou Q, Chen V, Shannon CP, et al. Interferon- $\alpha 2 b$ Treatment for COVID-19. Front Immunol. 2020; 11:1061.

Zuckier LS, Moadel RM, Haramati LB, et al. Diagnostic evaluation of pulmonary embolism during the COVID-19 pandemic. J Nucl Med. 2020; 61: 630-631.

Table 1. Main characteristics of included studies: Immunotherapy potentials (except vaccine) on Covid-19

\begin{tabular}{|c|c|c|c|c|c|}
\hline Treatment by & $\begin{array}{l}\text { Type of immunology } \\
\text { (vaccine and...) }\end{array}$ & $\begin{array}{l}\text { Accompanied by } \\
\text { another treatment }\end{array}$ & $\begin{array}{l}\text { Number of patient } \\
\text { treated }\end{array}$ & $\begin{array}{l}\text { Outcomes, } \\
\text { results and } \\
\text { relationship }\end{array}$ & Ref. \\
\hline Plasma therapy & $\begin{array}{l}\text { Polyclonal antibody } \\
\text { immune response }\end{array}$ & Standard treatment & $\begin{array}{l}300 \text { patients in } \\
\text { COVID-19 clinical } \\
\text { trial }\end{array}$ & $\begin{array}{l}\text { Clinical } \\
\text { improvement }\end{array}$ & $\begin{array}{l}\text { Zhang et al., } \\
2020\end{array}$ \\
\hline Immunoglobulin & ---- & Standard treatment & $\begin{array}{l}80 \text { patients in } \\
\text { COVID-19 clinical } \\
\text { trial }\end{array}$ & $\begin{array}{l}\text { Clinical } \\
\text { improvement }\end{array}$ & $\begin{array}{l}\text { Zhang et al., } \\
2020\end{array}$ \\
\hline Thymosin & $\begin{array}{l}\text { Polypeptide } \\
\text { hormone for } \\
\text { maturation of } \\
\text { T cells }\end{array}$ & $\begin{array}{l}\text { Camrelizumab } \\
\text { (anti PD-1 immune } \\
\text { checkpoint } \\
\text { inhibitor), } \\
\text { conventional } \\
\text { treatment }\end{array}$ & $\begin{array}{l}120 \text { patients in } \\
\text { COVID-19 clinical } \\
\text { trial }\end{array}$ & $\begin{array}{l}\text { Lung injury } \\
\text { score }\end{array}$ & $\begin{array}{l}\text { Zhang et al., } \\
2020\end{array}$ \\
\hline Tocilizumab & $\begin{array}{l}\text { Monoclonal } \\
\text { antibody against the } \\
\text { IL-6 receptor (IL- } \\
\text { 6R) }\end{array}$ & ----- & $\begin{array}{l}188 \text { patients in } \\
\text { COVID-19 clinical } \\
\text { trial }\end{array}$ & Cure rate & $\begin{array}{l}\text { Zhang et al., } \\
2020\end{array}$ \\
\hline $\begin{array}{l}\text { Tocilizumab } \\
\text { (Actemra) }\end{array}$ & $\begin{array}{l}\text { Monoclonal } \\
\text { antibody against IL- } \\
6 \text { inhibition- } \\
\text { reduction in } \\
\text { cytokine storm }\end{array}$ & ------ & $\begin{array}{l}21 \text { patients } \\
\text { In COVID-19 } \\
\text { clinical trial }\end{array}$ & Cure rate & Xu et al., 2020 \\
\hline Tocilizumab & $\begin{array}{l}\text { Monoclonal } \\
\text { antibody against IL- } \\
6 \text { inhibition- } \\
\text { reduction in } \\
\text { cytokine storm }\end{array}$ & $\begin{array}{l}\text { Conventional } \\
\text { therapy }\end{array}$ & $\begin{array}{l}188 \text { patients in } \\
\text { Covid-19 cliical trial }\end{array}$ & Cure rate & CCTR, 2000 \\
\hline Sarilumab & $\begin{array}{l}\text { Monoclonal } \\
\text { antibody against IL- } \\
6 \mathrm{R}\end{array}$ & ----- & $\begin{array}{l}300 \text { patients } \\
\text { Trials: Italy, Spain, } \\
\text { Germany, } \\
\text { France, Japan, } \\
\text { Canada and Russia }\end{array}$ & & $\begin{array}{l}\text { Eur. Pharm. } \\
\text { Reviev } \\
\text { Report, } 2020 .\end{array}$ \\
\hline $\begin{array}{l}\text { Immunoglobulin } \\
\text { Fc domain }\end{array}$ & $\begin{array}{l}\text { ACE2 } \\
\text { immnoadhesin }\end{array}$ & ----- & ----- & Untested & Kruse, 2020 \\
\hline $\begin{array}{l}\text { CR3022 (SARS- } \\
\text { CoV) }\end{array}$ & $\begin{array}{l}\text { Monoclonal } \\
\text { antibody (cross } \\
\text { reactive antibody) }\end{array}$ & $\begin{array}{l}\text { Alone or } \\
\text { combination with } \\
\text { other neutralizing }\end{array}$ & ----- & Untested & $\begin{array}{l}\text { Tian et al., } \\
2020\end{array}$ \\
\hline
\end{tabular}




\begin{tabular}{|c|c|c|c|c|c|}
\hline & & $\begin{array}{l}\text { antibody (e.g. m396, } \\
\text { CR3014) }\end{array}$ & & & \\
\hline Anakinra & $\begin{array}{l}\text { Recombinant human } \\
\text { nonglycosylated } \\
\text { interleukin-1 (IL-1) } \\
\text { receptor antagonist }\end{array}$ & $\begin{array}{l}\text { Conventional } \\
\text { therapy } \\
\text { (subcutaneous or } \\
\text { intravenous }\end{array}$ & $\begin{array}{l}\text { Different numbers } \\
\text { of patients in } \\
\text { France, Greece, } \\
\text { USA, Belgium and } \\
\text { UK }\end{array}$ & ------ & $\begin{array}{l}\text { Alijotas-Reig } \\
\text { et al., } 2020\end{array}$ \\
\hline $\begin{array}{l}\text { Convalescent } \\
\text { plasma transfusion }\end{array}$ & $\begin{array}{l}\text { Convalescent } \\
\text { plasma transfusion } \\
\text { from cure patients } \\
\text { rich containing } \\
\text { specific antibody } \\
\text { (IgG) }\end{array}$ & $\begin{array}{l}\text { Associated to } \\
\text { mechanical } \\
\text { ventilation, } \\
\text { interferon-alpha-1b } \\
\text { and favipiravid }\end{array}$ & $\begin{array}{l}5 \text { critical patients } \\
2 \text { remaining } \\
\text { hospitalized. } \\
3 \text { discharged home }\end{array}$ & Cure rate & $\begin{array}{l}\text { Shen et al., } \\
2020\end{array}$ \\
\hline $\begin{array}{l}\text { Systemic } \\
\text { anticoagulation }\end{array}$ & Not specified & $\begin{array}{l}\text { Associated to } \\
\text { mechanical } \\
\text { ventilation }\end{array}$ & 786 patients & Cure rate & $\begin{array}{l}\text { Paranjpe et al. } \\
2020\end{array}$ \\
\hline Heparin & Not specified & ----- & $\begin{array}{l}2075 \text { patients, } \\
\text { several hospitals in } \\
\text { Spain }\end{array}$ & Cure rate & $\begin{array}{l}\text { Ayerbe et al., } \\
2020\end{array}$ \\
\hline Heparin & $\begin{array}{l}\text { Low molecular } \\
\text { weight heparin }\end{array}$ & ----- & 99 patients & Cure rate & $\begin{array}{l}\text { Tang et al., } \\
2020\end{array}$ \\
\hline Statin & $\begin{array}{l}\text { One of them: } \\
\text { Atorvastatin, } \\
\text { fluvastatin, } \\
\text { pravastatin, } \\
\text { rosuvastatin, } \\
\text { simvastatin }\end{array}$ & ----- & 154 patients & Cure rate & $\begin{array}{l}\text { Dashti- } \\
\text { Khavidaki } \\
\text { and Khalili, } \\
\text { 2020) }\end{array}$ \\
\hline $\begin{array}{l}\text { Interferon } \\
\text { IFN- } \alpha 2 b\end{array}$ & $\begin{array}{l}\text { Presence and } \\
\text { absence of Arbidol }\end{array}$ & ----- & 77 patients & Cure rate & $\begin{array}{l}\text { Zhou et alk., } \\
2020\end{array}$ \\
\hline $\begin{array}{l}\text { Interferon } \\
\text { IFN- } \beta 1 \mathrm{~b}\end{array}$ & $\begin{array}{l}\text { Associated to } \\
\text { lopinavir-ritonavir, } \\
\text { and ribavirin, } \\
\text { compared with } \\
\text { single-drug } \\
\text { lopinavir-ritonavir i }\end{array}$ & ------- & 127 patients & Cure rate & $\begin{array}{l}\text { Hung et al., } \\
2020\end{array}$ \\
\hline Interferons & $\begin{array}{l}\text { Boosts the antiviral } \\
\text { immune response in } \\
\text { the early phase of } \\
\text { the disease }\end{array}$ & ------ & $\begin{array}{l}\text { A total of } 227 \\
\text { patients (4 trials) }\end{array}$ & Cure rate & $\begin{array}{l}\text { Saber-Ayad et } \\
\text { al. } 2020\end{array}$ \\
\hline BCG & $\begin{array}{l}\text { Several clinical } \\
\text { trials are in progress }\end{array}$ & ------ & $\begin{array}{l}\text { A total of } 17378 \\
\text { patients }\end{array}$ & Cure care & $\begin{array}{l}\text { Soliman et al. } \\
2020\end{array}$ \\
\hline OncoTherad & $\begin{array}{l}\text { Associated to } \\
\text { bladder cancer } \\
\text { treatment }\end{array}$ & $\begin{array}{l}\text { Patients refractory } \\
\text { to BCG treatment }\end{array}$ & 5 patients & $\begin{array}{l}\text { Cure care of } \\
\text { COVID-19 } \\
\text { infections }\end{array}$ & $\begin{array}{l}\text { Delafiori et } \\
\text { al., 2020; } \\
\text { MS-Brazil, } \\
2020\end{array}$ \\
\hline
\end{tabular}

